\title{
Substitution of the $\alpha$-lactalbumin transcription unit by a CAT cDNA within a BAC clone silenced the locus in transgenic mice without affecting the physically linked Cyclin $T 1$ gene
}

\author{
Solange Soulier ${ }^{\mathrm{a}}$, Marthe Hudrisier ${ }^{\mathrm{a}}$, \\ José Costa DA Silva ${ }^{\mathrm{a}}$, Caroline MAEDER ${ }^{\mathrm{b}}$, \\ Céline Viglietta ${ }^{\mathrm{b}}$, Nathalie Besnard ${ }^{\mathrm{a}}$, \\ Jean-Luc VILOTTE ${ }^{\text {a* }}$ \\ ${ }^{\text {a }}$ Laboratoire de génétique biochimique et de cytogénétique, \\ Département de génétique animale, Institut national de la recherche agronomique, \\ 78352 Jouy-en-Josas Cedex, France \\ b Laboratoire de biologie du développement et de biotechnologie, \\ Département de physiologie animale, Institut national de la recherche agronomique, \\ 78352 Jouy-en-Josas Cedex, France
}

(Received 12 December 2001; accepted 1 October 2002)

\begin{abstract}
We recently reported that a goat bacterial artificial chromosome (BAC) clone conferred site-independent expression in transgenic mice of the two loci present within its insert, the ubiquitously expressed Cyclin $T 1$ and the mammary specific $\alpha$-lactalbumin $(\alpha$ lac $)$ genes. To assess if this vector could target mammary-restricted expression of cDNA, the CAT ORF was introduced by homologous recombination in Escherichia coli in place of the $\alpha$ lac transcription unit. The insert of this modified BAC was injected into mice and three transgenic lines were derived. None of these lines expressed the CAT gene suggesting that the use of long genomic inserts is not sufficient to support the expression of intron-less transgenes. The physically linked goat $C y c l i n ~ T l$ locus was found to be active in all three lines. This observation reinforced the hypothesis that the two loci are localised in two separate chromatin domains.
\end{abstract}

bacterial artificial chromosome / homologous recombination / intron / transgenic mice / chromatin domain

\footnotetext{
* Correspondence and reprints
}

E-mail: vilotte@jouy.inra.fr 


\section{INTRODUCTION}

The use of long genomic fragments, such as bacterial artificial chromosome (BAC) or yeast artificial chromosome (YAC) inserts, is often associated with an appropriate expression of the gene of interest in transgenics, [7] for recent review. Subtle mutations of these fragments can be obtained by homologous recombination in Escherichia coli for BAC or in Yeast for YAC. These vectors are thus attractive either to assess the in vivo function of specific regulatory elements or to target the expression of foreign genes using hybrid constructs.

We recently reported that a $160 \mathrm{~kb}$ goat BAC insert conferred position independent, copy-number-related, tissue-specific and developmentally regulated expression to the $\alpha$ lac gene in transgenic mice [15] as well as positionindependent, ubiquitous expression of the physically linked Cyclin $T 1$ gene [9]. To assess if this vector could target mammary-specific expression of a cDNA, we inserted the chloramphenicol acetyl-transferase (CAT) gene in place of the $\alpha$ lac transcription unit (TU) by homologous recombination in Escherichia coli. We report that this substitution silenced the modified goat $\alpha$ lac locus in transgenic mice without affecting the expression of the Cyclin $T 1$ gene.

\section{MATERIALS AND METHODS}

\subsection{Modification of the BAC insert by homologous recombination in Escherichia coli}

Substitution of the $\alpha$ lac TU by the CAT open reading frame (ORF) was performed using the procedure of Yang et al. [18]. To do this, a $800 \mathrm{bp} \mathrm{long}$ fragment encompassing $760 \mathrm{bp}$ of the goat $\alpha$ lac promoter alongside the first $10 \mathrm{bp}$ of the $5^{\prime}$ UTR of exon 1 of the gene was amplified by PCR using the BAC DNA as the template and oligos 5' GGTCGACTTATATATTTATGAACACATTTA 3' and 5' CCCGGGATAACTTCGTATAATGTATGCTATACGAACGGTATCCTGAAATGGGGTCACCACACT $3^{\prime}$. The second primer contains at its $5^{\prime}$ end a LoxP sequence. This site was inserted to potentially allow subsequent integration of various reporter genes within the $5^{\prime}$ UTR of the modified $\alpha$ lac locus. The amplified fragment was cloned into pUC19 and sequenced. A second fragment of $650 \mathrm{bp}$ encompassing the $3^{\prime} \mathrm{UTR}$ of $\alpha$ lac exon IV alongside $350 \mathrm{bp}$ of the $3^{\prime}$ flanking region was amplified by PCR, using the BAC DNA as template and the primers $5^{\prime}$ CCTGCAGTCTTTGCTGCTTCTGTCCTCTTTC $3^{\prime}$ and 5' GGTCGACAGCTCACCAGGCCTCCCTGTCCCT 3'. Again, this fragment was cloned into pUC 19 and sequenced. Lastly, the CAT ORF was released and purified away from the pB9 CAT recombinant plasmid [17] by a HincII/PstI digestion. By sequential cloning, the SalI/SmaI goat $\alpha$ lac promoter fragment was linked to the CAT HincII/PstI cDNA using the two blunt restriction sites and the resulting fragment linked to the PstI/SalI goat 
$\alpha$ lac $3^{\prime}$ UTR and flanking region using the PstI site. The functionality of this gene was assessed by transient transfection in CHO-K1 cells, as previously described [13] and data not shown. The entire SalI insert was then released and subcloned into the corresponding site of the pSV1. RecA shuttle vector [18].

\subsection{Generation of transgenic mice}

Isolation and micro-injection of the modified BAC insert was performed as previously described [15]. Transgenic mice were identified both by Southern blotting of PstI digested genomic DNA and by PCR. The blots were probed with a CAT probe. The set of primers designed to amplify the goat $\alpha$ lac promoter region were used for PCR.

\section{RESULTS AND DISCUSSION}

\subsection{Modification of the $\mathrm{BAC}$ insert}

Following the experimental procedure described in Yang et al. [18], Southern analysis revealed that co-integration by homologous recombination of the shuttle vector within the BAC insert was achieved in two out of the twenty-four colonies screened. In the second step of the procedure, the cointegrates were then resolved by selecting against the tetracycline marker and one out of the forty-eight colonies analysed was found to contain a correct modified BAC, as judged by Southern blot analysis. The schematic structures of the original and modified BACs are given in Figure 1. RFLP analysis and determination of the size of the modified BAC were performed to ensure that no unexpected deletions or insertions occurred during this process (Fig. 2).

\subsection{Generation of transgenic mice}

Following micro-injection of the modified BAC insert, three transgenic lines were obtained (263, 271 and 272). Southern blots demonstrated that lines 263 and 271 contain multiple copies of the modified BAC insert since the Pst I CAT-hybridising fragment signals were more intense with DNA from mice from these two lines compared to animals from line 272 (Fig. 3A and data not shown). The occurrence of the edges of the transgene was confirmed by PCR in the three lines as previously described [15].

\subsection{The modified $\alpha$ lac locus is silenced}

Analysis of the CAT transgene expression was performed on 7-day lactating G1 females from each established line using the method of Gorman et al. [8]. No expression was detected in the six tissues tested, including the mammary 

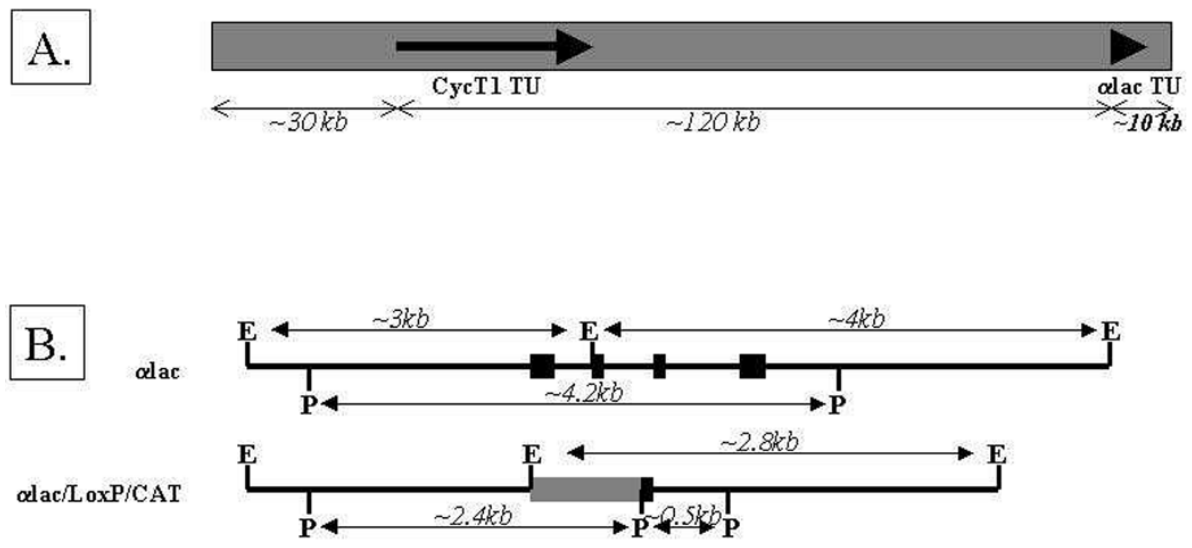

Figure 1. Schematic representation of the original and modified BACs and RFLP analyses.

A: Schematic representation of the $160 \mathrm{~kb}$ goat BAC41 insert. Localisation of the transcription unit of the two genes are indicated by arrows. Length of these transcription units are not at scale. The $\alpha$ lac transcription unit is $2 \mathrm{~kb}$ in length whereas the size of the CycT1 transcription unit is of at least $30 \mathrm{~kb}$.

B: Schematic representation of the intact $\alpha$ lac TU and of the $\alpha$ lac/LoxP/CAT shuttle vector that was introduced into the original BAC. Black boxes: $\alpha$ lac exons. Grey box: CAT cDNA. E: EcoRI; P: PstI. Estimated sizes of the EcoRI and PstI restriction fragments are indicated. Exons are not at scale.

gland (Fig. 3B and data not shown). To assess if this lack of enzymatic activity could result from the synthesis of a non functional mRNA due to a cryptic splicing event as already described by others [19], Northern blotting analyses were performed. Using a CAT cDNA probe, no hybridisation signal was observed, strongly suggesting that the locus was transcriptionally inactive in the three lines.

The $\alpha$ lac promoter has been successfully used in various transgenic experiments to target mammary expression of reporter genes $[4,5,10,13,16]$. Since the TU of the $\alpha$ lac gene was absent from these transgenes, our current observation cannot be simply explained by the occurrence of an essential cis-regulatory element within this region.

Introns are known to enhance the expression of transgenes [2,11]. We have intentionally chosen to use an intronless construct to assess if this was still the case when the gene was inserted in a long genomic fragment, mimicking somehow the natural favourable chromatin environment. The observed results strongly suggest that introns are needed for a locus to be identified by the cell transcriptional machinery, even when surrounded by most if not all the cis-regulatory elements that regulate its expression. 


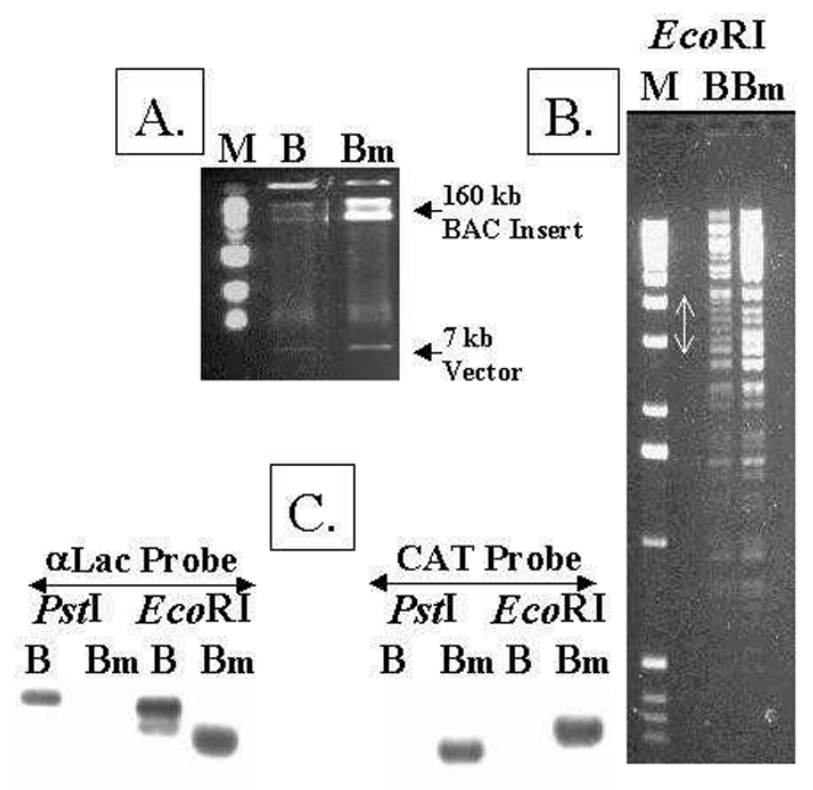

Figure 2. RFLP analyses of the original and modified BACs.

A: Size estimation of the original and modified BAC inserts. NotI-digested BAC DNAs were fractionated by PFGE. M: MidRange II PFG Markers (Biolabs). B: Original BAC. Bm: modified BAC.

B: RFLP analysis of EcoRI-digested original and modified BAC DNAs. M: $1 \mathrm{~kb}$ DNA ladder (Gibco BRL). B: Original BAC. Bm: Modified BAC. The arrow indicates the region were the banding pattern differs between the two BACs, due to the recombination event.

C: Southern blotting analyses of the original and modified BAC DNAs. B: Original BAC. Bm: Modified BAC. Restriction enzymes and probes used are indicated on the top. Numbers and sizes of the revealed restriction fragments are conformed to the restriction map given in Figure 1B.

\subsection{Expression of the Cyclin $T 1$ gene is unaffected}

We recently reported that the original BAC clone also contains the locus of the Cyclin Tl gene which was found to be functional and ubiquitously expressed in transgenic mice [9]. Expression of this gene was assessed by RT-PCR in the three transgenic lines obtained with the modified BAC. It revealed that the 
A.
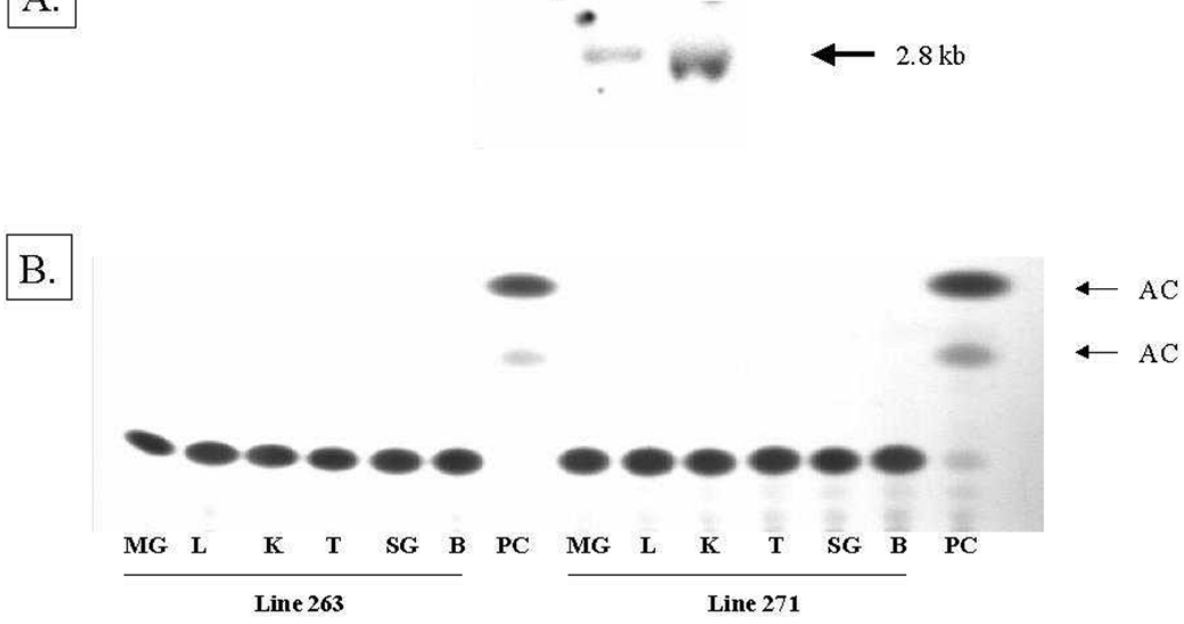

Figure 3. Detection of transgenic mice and CAT expression analysis.

A: Detection of transgenic mice by Southern analysis of Pst $\mathrm{I}$-digested genomic DNA. The origin of the genomic DNAs are indicated on the top lane. N.Tg.: non-transgenic mice. 272 and 271: transgenic offspring of founder mouse 272 and 271, respectively. The membrane was probed with the CAT cDNA. The size of the hybridising fragments was estimated at $2.8 \mathrm{~kb}$, and is thus conform to the map given in Figure 1B.

B: CAT expression analysis. CAT assays were performed according to Gorman et al. [8] using $100 \mu \mathrm{g}$ of protein extract per sample. CAT assays were performed for 4 or $16 \mathrm{~h}$, with no difference on the results. MG: mammary gland; L: liver; K: kidney; T: thymus; SG: salivary gland; B: brain; PC: positive control sample. AC: Acetylated chloramphenicol forms, resulting from the CAT activity. The common band that appears in all samples is the non-acetylated chloramphenicol.

gene was expressed (Fig. 4). This result highlighted once more the independent regulation of the two loci.

It was recently suggested that the CAT reporter sequence could serve as an active focus for gene silencing [3]. This silencing effect was shown to affect the adjacent transgenes. Thus our result strongly suggests that the Cyclin $\mathrm{Tl}$ and the $\alpha$ lac genes are separated by a boundary which blocks propagation of the silencing effect $[1,6]$. In other words, these two genes appear to be located in two different chromatin domains.

Insulators defined independent chromatin domains of gene expression [1, 6]. We have already suggested that such an element might be located between the Cyclin $T 1$ and the $\alpha$ lac loci $[9,14]$. The present result reinforces this hypothesis. Such an element was recently localised between two independentlyregulated, physically closely-linked genes [12], a situation very similar to the one described here. 


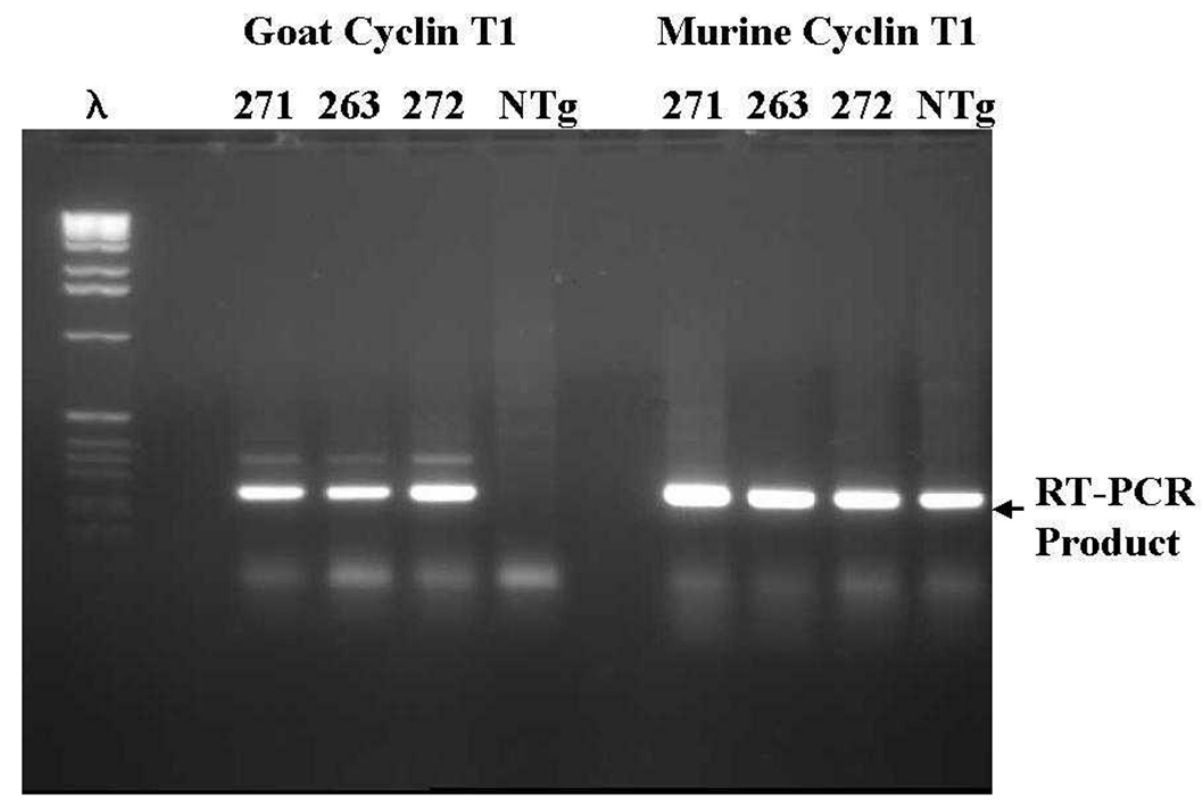

Figure 4. Expression analysis of goat and murine $C y c l i n T 1$ by RT-PCR. The reverse transcription step was performed using $10 \mu \mathrm{g}$ of total RNA from 7-day lactating mammary gland samples. Reverse transcription and PCR were performed as described in [9]. PCR was performed using sets of oligonucleotides that were either specific of the goat or of the mouse gene [9]. Since the oligonucleotides used are located in exon 1 and 3 of the Cyclin Tl gene, the size of the PCR product indicates that it derives from a cDNA. NTg: non-transgenic mice. Detection of the murine Cyclin T1 mRNA in the NTg sample indicates that the reverse transcription step worked. $\lambda: 1 \mathrm{~kb}$ DNA ladder (Gibco BRL).

\section{ACKNOWLEDGEMENTS}

We are most grateful to Xiangdong Yang (Rockefeller University, New York, USA) for the kind gift of the $p S V 1-R e c A$ vector, to Xavier Mata (LGBC, Inra) for the Cyclin $T 1$ oligonucleotides, to Louis-Marie Houdebine (LBDB, Inra) for allowing the micro-injection to be also performed in his laboratory and to Edmond Paul Cribiu (LGBC, Inra) for his support.

\section{REFERENCES}

[1] Bell A.C., Felsenfeld G., Stopped at the border: boundaries and insulators, Curr. Opin. Genet. Dev. 9 (1999) 191-198.

[2] Brinster R.L., Allen J.M., Behringer R.R., Gelinas R.E., Palmiter R.D., Introns increase transcriptional efficiency in transgenic mice, Proc. Natl. Acad. Sci. USA 85 (1988) 836-840. 
[3] Clark A.J., Harold G., Yull F.E., Mammalian cDNA and prokaryotic reporter sequences silence adjacent transgenes in transgenic mice, Nucleic Acids Res. 25 (1997) 1009-1014.

[4] Fujiwara Y., Miwa M., Takahashi R.I., Kodaira K., Hirabayashi M., Suzuki T., Ueda M., High level expressing YAC vector for transgenic animal bioreactors, Mol. Reprod. Develop. 52 (1999) 414-420.

[5] Fujiwara Y., Takahashi R.I., Miwa M., Mameda M., Kodaira K., Hirabayashi M., Suzuki T., Ueda M., Analysis of control elements for position-independent expression of human $\alpha$-lactalbumin YAC, Mol. Reprod. Develop. 54 (1999) $17-23$.

[6] Geyer P.K., The role of insulator elements in defining domains of gene expression, Curr. Opin. Genet. Dev. 7 (1997) 242-248.

[7] Giraldo P., Montoliu L., Size matters: use of YACs, BACs and PACs in transgenic animals, Transg. Res. 10 (2001) 83-103.

[8] Gorman C.M., Moffat L., Howard B.H., Recombinant genomes which express chloramphenicol acetyltransferase in mammalian cells, Mol. Cell. Biol. 2 (1982) 1044-1051.

[9] Mata X., Vilotte J.L., Ubiquitous expression of goat cyclin T1 in transgenic mice, Transg. Res. 11 (2002) 65-68.

[10] Ninomiya T., Hirabayashi M., Sagara J., Yuki A., Functions of milk protein gene $5^{\prime}$ flanking regions on human growth hormone gene, Mol. Reprod. Develop. 37 (1994) 276-283.

[11] Palmiter R.D., Sandgren E.P., Avarbock M.R., Allen D.D., Brinster R.L., Heterologous introns can enhance expression of transgenes in mice, Proc. Natl. Acad. Sci. USA 88 (1991) 478-482.

[12] Prioleau M.N., Nony P., Simpson M., Felsenfeld G., An insulator element and condensed chromatin region separate the chicken $\beta$-globin locus from an independently regulated erythroid-specific folate receptor gene, EMBO J 18 (1999) 4035-4048.

[13] Soulier S., Lepourry L., Stinnakre M.G., Langley B., L'Huillier P.J., Paly J., Djiane J., Mercier J.C., Vilotte J.L., Introduction of a proximal Stat5 site in the murine $\alpha$-lactalbumin promotor induces prolactin dependency in vitro and improves expression frequency in vivo, Transg. Res. 7 (1998) 1-9.

[14] Soulier S., Stinnakre M.G., Costa Da Siva J., Lepourry L., Mata X., Besnard N., Vilotte J.L., Distal element(s) is(are) required for position-independent expression of the goat $\alpha$-lactalbumin gene in transgenic mice. Potential relationship with the location of the cyclin T1 locus, Genet. Sel. Evol. 32 (2000) 621-630.

[15] Stinnakre M.G., Soulier S., Schibler L., Lepourry L., Mercier J.C., Vilotte J.L., Position-independent and copy-number-related expression of a goat bacterial artificial chromosome $\alpha$-lactalbumin gene in transgenic mice, Biochem. J. 339 (1999) 33-36.

[16] Stinnakre M.G., Vilotte J.L., Soulier S., L'Haridon R., Charlier M., Gaye P., Mercier J.C., The bovine $\alpha$-lactalbumin promoter directs expression of ovine trophoblast interferon in the mammary gland of transgenic mice, FEBS Letters 284 (1991) 19-22. 
[17] Whitelaw C.B.A., Wilkie N.M., Jones K.A., Kadonaga J.T., Tjian R., Lang J.C., Transcriptionally active domains in the $5^{\prime}$ flanking sequence of human c-myc, UCLA Symp. Mol. Biol. 58 (1988) 337-351.

[18] Yang X.W., Model P., Heintz N., Homologous recombination based modification in Escherichia coli and germline transmission in transgenic mice of a bacterial artificial chromosome, Nat. Biotech. 15 (1997) 859-865.

[19] Yull F., Harold G., Wallace R., Cowper A., Percy J., Cottingham I., Clark A.J., Fixing human factor IX (fIX): Correction of a cryptic RNA splice enables the production of biologically active fIX in the mammary gland of transgenic mice, Proc. Natl. Acad. Sci. USA 92 (1995) 10899-10903.

To access this journal online: www.edpsciences.org 